Günter Wohlfart · Der spekulative Satz 



\section{Günter Wohlfart}

\section{Der spekulative Satz}

Bemerkungen zum Begriff der Spekulation bei Hegel

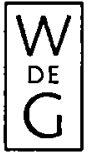

Walter de Gruyter - Berlin · New York 1981 
Gedruckt mit Unterstützung der Deutschen Forschungsgemeinschaft

Die vorliegende Arbeit wurde in geringfügig abgeänderter Form 1978 vom Fachbereich Philosophie der Universität Tübingen als Habilitationsschrift anerkannt.

CIP-Kurztitelaufnabme der Deutschen Bibliothek

\section{Wohlfart, Günter:}

Der spekulative Satz : Bemerkungen zum Begriff d. Spekulation bei Hegel / Günter Wohlfart. - Berlin, New York : de Gruyter, 1981.

ISBN 3-11-008111-3

(c)

1980 by Walter de Gruyter \& Co., vormals G. J. Göschen'sche Verlagshandlung · J. Guttentag, Verlagsbuchhandlung - Georg Reimer - Karl J. Trübner - Veit \& Comp., Berlin 30, Genthiner Straße 13. Printed in Germany

Alle Rechte, insbesondere das der Ubersetzung in fremde Sprachen, vorbehalten. Ohne ausdrückliche Genehmigung des Verlages ist es auch nicht gestattet, dieses Buch oder Teile daraus auf photomechanischem Wege (Photokopie, Mikrokopie, Xerokopie) zu vervielfältigen. Satz und Druck: Arthur Collignon GmbH, Berlin

Einband: Lüderitz \& Bauer, Berlin 